\title{
Treatment of Obsessive Compulsive Disorder and excessive reassurance seeking in an older adult: a single case quasi-experimental design
}

Article

Accepted Version

Halldorsson, B. and Salkovskis, P. M. (2017) Treatment of Obsessive Compulsive Disorder and excessive reassurance seeking in an older adult: a single case quasi-experimental design. Behavioural and Cognitive Psychotherapy, 45 (6). pp. 616-628. ISSN 1352-4658 doi: https://doi.org/10.1017/S1352465817000376 Available at https://centaur.reading.ac.uk/70401/

It is advisable to refer to the publisher's version if you intend to cite from the work. See Guidance on citing.

To link to this article DOI: http://dx.doi.org/10.1017/S1352465817000376

Publisher: Cambridge University Press

All outputs in CentAUR are protected by Intellectual Property Rights law, including copyright law. Copyright and IPR is retained by the creators or other copyright holders. Terms and conditions for use of this material are defined in the End User Agreement. 


\section{www.reading.ac.uk/centaur}

\section{CentAUR}

Central Archive at the University of Reading

Reading's research outputs online 
Treatment of OCD and Excessive Reassurance Seeking in an Older Adult: A Single Case Quasi-Experimental Design

\author{
Brynjar Halldorsson ${ }^{a^{*}}$ and Paul M. Salkovskis ${ }^{\mathrm{a}}$

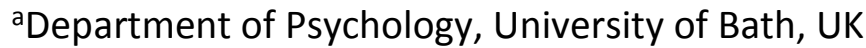

*Address for correspondence:

Brynjar Halldorsson,

School of Psychology and Clinical Language Sciences,

University of Reading, RG6 6AL, UK

Telephone: +44 (0) 1183788579

Email: b.halldorsson@reading.ac.uk

Fax: +44 (0) 1183786715

Keywords: Reassurance seeking, OCD, single case experimental design, CBT

Acknowledgements: We wish to thank Catherine Green and Victoria Oldfield for all their advice and assistance.

Conflict of Interest: Brynjar Halldorsson and Paul Salkovskis have no conflict of interest with respect to this publication.

Financial support: This research received no specific grant from any funding agency, commercial or not-for-profit sectors.

The authors assert that all procedures contributing to this work comply with the ethical principles of psychologists and code of conduct as set out by the APA. Ethical approval was granted through University of Bath. 


\begin{abstract}
Background: Cognitive behavioural interventions for excessive reassurance seeking (ERS) typically focus on encouraging individuals to refrain from seeking any reassurance and in some cases banning caregivers (e.g. family members) from providing it. However, this blanket consideration that reassurance is a bad thing that should simply be stopped may not always be appropriate or helpful. Cognitive behavioural treatment targeting ERS by helping the sufferer to shift from seeking reassurance to seeking support may be a promising treatment intervention.
\end{abstract}

Aims: This study aims to examine the targeted treatment of ERS in an older adult who has been suffering from severe Obsessive Compulsive Disorder (OCD) for seven decades

Method: Using a single case quasi-experimental design $(A B C D)$, the frequency of reassurance seeking, urges to seek reassurance, OCD beliefs and anxiety were measured daily for almost a year in addition to standard symptom measures.

Results: At the end of treatment, visual inspection showed that reassurance seeking was no longer considered excessive and OCD severity fell from the severe to non-clinical range across the treatment sessions. All treatment gains were maintained at follow-up.

Conclusions: This study illustrates how CBT can be successfully applied to treat long standing OCD and ERS in an older adult. Engendering support as an alternative to reassurance seeking in CBT may be a particularly promising intervention for ERS. 


\section{Introduction}

Studies examining 'symptom accommodation' within the context of OCD have indicated that excessive reassurance seeking (ERS) is one of the most common manifestations of accommodation across adult and pediatric samples (Peris et al., 2008; Shafran, Ralph, \& Tallis, 1995; Stewart et al., 2008; Storch et al., 2007). Although the number of studies examining ERS has increased over the last few years (e.g. Halldorsson, Salkovskis, Kobori, \& Pagdin, 2016; Kobori \& Salkovskis, 2013; Kobori, Salkovskis, Read, Lounes, \& Wong, 2012; Parrish \& Radomsky, 2010, 2011; Salkovskis \& Kobori, 2015), ERS still remains a relatively under-researched and poorly understood behaviour.

Requests for reassurance, in whatever form they take, can reduce a felt sense of threat and therefore relieve anxiety. However, the effects are typically short lived and reassurance then tends to be sought over and over again similar to the repetition seen in checking rituals, of which we argue reassurance seeking is a subtype. The return of the urge to seek reassurance and anxiety is most likely to be a result of the return or even increase in perceived threat (Salkovskis \& Kobori, 2015; Salkovskis \& Warwick, 1986). This may arise from doubting focused on the reassuring information, loss of confidence in memory for the previous reassurance, increased accessibility and/or elaboration of threat ideas and so on.

Within the cognitive and behavioural treatment literature it is commonly recommended that therapists simply withhold any reassurance giving and strongly encourage patients not to seek it, and even tell their carers not to provide it (Abramowitz, Franklin, \& Cahill, 2003; Marks, 2005; Rachman, 2002). However, it remains unclear to what extent therapists use this particular approach in treatment. This intervention originates in behaviour theory and is 
based on the idea that the transient reductions in feelings of anxiety and the potential relief that may follow the provision of reassurance reinforces the behaviour, and thus any requests for reassurance should be ignored to allow the behaviour to be extinguished by a process of non-reinforcement (Abramowitz et al., 2003; Rachman, 2002; Rachman \& Hodgson, 1980). In other words, these procedures are meant to demonstrate to the patient that their distress naturally subsides over time, and thus seeking reassurance is not necessary. However, this blanket consideration that reassurance is a bad thing that should simply be stopped may not always be appropriate or helpful. But why? ERS is a highly evolved repetitive and usually negotiated interpersonal behaviour - it is between people, as opposed to, for example, compulsive washing or other checking behaviours which tend to be performed when the person is alone (Rachman, 1976, 2002). Also, the behavioural approach does not take into account interpersonal factors and is entirely focused on the fact that the patient has sought reassurance rather than trying to weaken the belief that motivates the patient's behaviour - so that the person seeking excessive reassurance chooses not to engage in the behaviour. Furthermore, experienced therapists may be well equipped and feel competent to deal with the negative reactions, both the behavioural and emotional, which withholding reassurance may elicit, but caregivers of anxiety sufferers are typically not. Recent studies have also suggested that caregivers often feel like they cannot cope without providing reassurance and withholding it can have negative consequences (e.g. aggression, violence) (Halldorsson, Salkovskis, Kobori, \& Pagdin, 2015). If it is assumed that reassurance seeking is a compulsive behaviour, then simply making it externally unavailable is unlikely, in most cases, to be either acceptable or actually helpful. We would not lock the bathroom to patients who wash, or remove the lock from the door of someone who checks. It won't work. 
A related issue concerns treatment acceptability. Recommended treatments such as Exposure and Response Prevention (ERP) and Cognitive Behavioural Therapy (CBT) have unacceptably high attrition rates (Foa et al., 2005; Houghton, Saxon, Bradburn, Ricketts, \& Hardy, 2010) - although this has recently been questioned (Ong, Clyde, Bluett, Levin, \& Twohig, 2016) - often because patients find these treatments too difficult to tolerate (Shafran, Radomsky, Coughtrey, \& Rachman, 2013). Consequently, there has been a call for developing ways to increase treatment acceptability without comprising efficacy. For ERS one such way may be to help people to shift from seeking reassurance to seeking support presented within a 'Theory A versus Theory B' perspective (Salkovskis, 1999) where support seeking functions as a coping response where the person intends to control his/her anxiety with no further beliefs about the benefits of the response (Salkovskis, 1996a, 1996b). It is important to note that support seeking is here defined with reference to 'coping with distress' but not 'saving' the person from threat as we would expect for safety-seeking behaviours such as ERS (Salkovskis, 1991). From a theoretical perspective, support seeking is here understood to represent the opposite to safety-seeking behaviour. Specifically, when a person seeks support the intention is to seek help to cope with the distress and this interaction influences the sufferer's anxiety problem by providing him/her a sense of control, encouragement and/or a belief that he/she can overcome the distress (or accept the anxiety for what it is). This is entirely different from ERS which is focused on 'saving' the person (or others he/she feels responsible for) from threat or its consequences and transferring responsibility onto another person (Halldorsson \& Salkovskis, 2017). However, the potential therapeutic gains of support seeking remain mostly unexamined and to the author's knowledge, controlled experimental analysis do not exist examining the effects of helping OCD sufferers to shift from seeking reassurance to seeking support. 
The following single case quasi-experimental design describes CBT treatment based on Salkovskis (1985) cognitive model of OCD for an older adult who frequently engages in ERS as part of his longstanding and treatment refractory contamination related OCD. The participant's, frequency of reassurance seeking, feelings of anxiety, urges to seek reassurance, OCD beliefs and OCD symptoms were measured and observed repeatedly over a period of 15 months. At the start of treatment, the participant had been suffering from OCD symptoms for approximately seven decades, or since he was a young child, and spent many hours every week (sometimes daily) obsessively washing himself, his clothes or other objects after having come in contact with 'contaminated' objects.

\section{Method}

\section{Quasi-Experimental Design}

A single case series using an $A B C D$ quasi-experimental design (Barlow, Nock, \& Hersen, 2008) with two follow-up measurements was implemented. The participant was assigned to a no-treatment baseline for 21 days (A). During the baseline, the participant took daily ratings of his OCD beliefs, feelings of anxiety and reassurance seeking and more (see below). Following baseline measures, CBT treatment was implemented which involved three phases, i.e. $\mathrm{B}^{1}, \mathrm{~B}^{1} \mathrm{~B}^{2}$, and $\mathrm{B}^{1} \mathrm{~B}^{2} \mathrm{~B}^{3}$. The treatment phase is expressed in this way to account for the expected (and intended) carryover effects (Barlow et al., 2008). The next phase was the relapse prevention phase (C), followed by a monitoring phase (D). Treatment sessions were offered once a week at the beginning of treatment, but as treatment progressed the time between sessions was extended. Daily ratings were continued over a period of 15 months as well as monitoring of OCD symptoms using standard clinical measures. On completion of 
treatment, the patient was followed up for 1 and 6 months (monitoring phase; D). No CBT was offered between post-treatment and follow-up intervals.

\section{Participant}

"Nick" (not patient's real name), presented to an outpatient specialist anxiety clinic as a 78 year old married male suffering from severe and long-standing symptoms of contamination OCD. Nick had suffered from OCD since he was 5 years old and had a history of being hospitalized twice (in the 1970s and 1980s) due to his OCD. During his hospital stays he received minimal treatment. His OCD had taken many 'forms' over the years, but was mainly focused on contamination both mental and physical. He had been offered CBT twice in the past 4 years (12 sessions each time). On both occasions, he found these treatment courses to be helpful as they reduced his OCD symptoms but quickly after discharge he relapsed. Neither treatment had specifically focused on treating his ERS. When starting this course of treatment, he was living with his partner and they had three children (who lived elsewhere). Nick gave his consent for details of this case and treatment to be published. Some details of his case history have been altered to anonymise the account.

\section{Daily Ratings of Excessive Reassurance Seeking, Anxiety, Urges and OCD belief}

The following outcome variables were identified during the initial assessment: (i) A count of 'how often reassurance was sought on that day' (on a visual analogue scale ranging from 0 to 100 ), (ii) 'experienced anxiety throughout the day' (on a visual analogue scale ranging from 0 to 100), (iii) 'urge to seek reassurance throughout the day' (on a visual analogue scale ranging from 0 to 100 ), (iv) 'the strength of the OCD belief that day, i.e. "I am contaminated and unless I do something about it I will be on the road to death". 
This semi-idiographic measure was administered on a daily basis during baseline measurement (21 days), during treatment and relapse prevention (291 days; 16 treatment sessions and 2 relapse sessions) apart from 7 days when the participant was on holiday. The participant was asked to fill in the measure for 1-2 weeks prior to attending the 1 month and 6-month follow-up appointments. The participant was given the forms in a paper format and asked to fill them in every evening.

Diagnostic tools and symptom measures

The following measures were used in the intake session and during treatment: The Structured Clinical Interview for Diagnostic and Statistical Manual for DSM-IV Axis I Disorders (SCID; First, Spitzer, Gibbon, \& Williams, 1996); The Yale-Brown Obsessive Compulsive Scale (Y-BOCS; Goodman et al., 1989); The Obsessive Compulsive Inventory Distress Scale (OCl; Foa, Kozak, Salkovskis, Coles, \& Amir, 1998); The Patient Health Questionnaire-9 (PHQ-9; Kroenke, Spitzer, \& Williams, 2001); Generalised Anxiety Disorder-7 (GAD-7; Spitzer, Kroenke, Williams, \& Lowe, 2006); The Work and Social Adjustment Scale (WSAS; Mundt, Marks, Shear, \& Greist, 2002); Responsibility Attitude Scale (RAS; Salkovskis et al., 2000); Responsibility Interpretations Questionnaire - Belief (RIQ-B; Salkovskis et al., 2000); OCD Weekly Outcome Score (OCD-WOS; Salkovskis, unpublished). This is a 4-item unpublished self-report measure. Respondents rate: (i) how much time each day they have been occupied by their obsessions and/or compulsions (ranging from 0 hours to $>7$ hours); (ii) how distressed they have felt; (iii) how much handicap the OCD has caused them; and (iv) levels of avoidance as a result of their obsessions and/or compulsions. Items 2-4 are graded on a 8-point scale from none/not at all (0) to extreme/always (8). 


\section{Procedure}

The participant started treatment after 3 weeks of baseline measurements ( 21 data points). He was offered (and attended) 16 treatment sessions, 2 relapse prevention sessions and two follow-up appointments. The initial 6 sessions lasted for 1.5 hours and the remaining sessions were an hour long, meaning that in total he received approximately 21 hours of CBT treatment. The clinical contact was spread over 15 months. Each session was recorded using a video and audio recording device (which Nick listened to between sessions).

The treatment was based on Salkovskis (1985) cognitive model of OCD and outlined in Salkovskis (1999). In summary, the treatment consisted of the following components: Assessment and idiographic formulation, socialisation to the cognitive and behavioural model, goal setting, cognitive work on key OCD beliefs and reassurance seeking, including theory A versus theory B approach, repeated behavioural experiments aimed at testing out contamination fears and the effects of various behavioural responses (including excessive reassurance seeking), reclaiming life following $O C D$, relapse prevention, including 'blueprint' work and booster sessions.

Sessions were divided into six different phases, i.e. baseline $(A)$, three treatment phases $\left(B^{1}\right.$; $\left.B^{1} B^{2} ; B^{1} B^{2} B^{3}\right)$, relapse prevention $(C)$, and a monitoring phase (D). Each phase was as follows: Baseline measurement $(A)$ - following initial assessment baseline measurements were taken over 21 days; First treatment phase $\left(B^{1}\right)$ - This includes the first four treatment sessions which focused on formulating Nick's presenting problem, specifically helping him to understand how his OCD was maintained and exploring why he had relapsed following his previous CBT treatment courses. This involved drawing out his idiographic formulation, which depicted all his maintenance factors and Nick was helped to approach his OCD 
problem from a different perspective (theory A versus theory B). During this phase, Nick's 'use' of excessive reassurance seeking was also explored and it was identified as an important maintenance factor. Nick mainly sought reassurance from his wife. In any given situation, Nick would usually ask repeatedly for reassurance. According to Nick, his ERS was causing problems in his relationship, such as arguments and he described his partner as being "fed up" and frustrated by his ERS. Nick said that he found it very hard to refrain from seeking reassurance and felt unable to cope without it. During this phase, Nick was helped to understand, using the theory A/B approach how seeking reassurance, as well as other compulsions (e.g. compulsive washing), were unhelpful and served to maintain his problem; Second treatment phase $\left(B^{1} B^{2}\right)-$ This includes treatment sessions 5 to 9 . During this phase, Nick started to challenge his contamination fears within the context of behavioural experiments (e.g. deliberately contaminate himself and refrain from compulsive washing). Gradually, these experiments became more challenging; Nick took more responsibility in devising them and they moved from 'in-session experiments' to experiments done in areas of the city or at places (e.g. hospitals) that Nick found particularly dangerous; Third treatment phase $\left(B^{1} B^{2} B^{3}\right)$ - This includes treatment sessions 10 to 15 . During this phase, other compulsions, in particular ERS, received increasingly more treatment attention. With regards to ERS specifically, this phase of intervention began with extensive discussion of the way in which ERS was different from other compulsions due to its interpersonal processes. Using the theory A/B framework Nick was helped to examine how ERS was both unhelpful and unnecessary. He was introduced to the idea (and helped to practice) engaging in support seeking instead of reassurance. Nick's partner took more part in the treatment at this stage. She attended therapy sessions (and took part in home-visits) where the intervention of shifting from reassurance seeking to support seeking was discussed 
extensively and practiced. For example, instead of seeking reassurance, Nick would share with his partner how he was feeling, and ask for encouragement to overcome the urge to engage in a compulsive behaviour (i.e. ERS); Relapse prevention (C) - After 16 sessions of treatment the relapse prevention phase began. During sessions 16 to 18 , Nick was helped to write up a 'blueprint', which summarises everything he had learnt in treatment and set up a plan (in writing) of what he could do if the OCD got worse again. It should be acknowledged that behavioural experiments were constantly implemented throughout treatment - even during the relapse prevention phase - where Nick continued to set himself bigger targets to challenge his fears. This included travelling abroad and re-connecting with old friend, some of which he had been unable to do for many years due to his contamination fears; Monitoring phase (D) - Having completed 18 sessions of treatment (and relapse prevention) the treatment ended. Nick was seen 1 and 6 months after the close of the treatment intervention for an assessment.

\section{Data Analysis}

Due to the large amount of data points weekly moving average values (average of 7 days) were calculated. Data were displayed graphically for the data evaluation, which consisted of visual inspection of medians, trends (slope), and variability between phases. Level lines (median scores for the last seven data points in each phase) are presented in black dotted lines and represent where the participant's scores ended up at end of each phase.

\section{Results}

Daily Ratings of ERS, Anxiety, Urges and OCD Belief - Visual Inspection

Figure 1 depicts the patterns of the daily visual analogue scale ratings for the frequency of reassurance seeking. Figure 2 depicts the pattern of the daily visual analogue scale ratings 
for feelings of anxiety. Ratings for 'urges to seek reassurance' and 'OCD belief' are visually represented in the supplementary material of the paper. The first treatment phase (Tx Phase 1) focused on 'making sense of the problem' by developing an idiographic formulation and introducing to Nick the idea of approaching his OCD problem using theory $A$ versus theory B framework. By comparing level lines across the Baseline phase with the first treatment phase (Tx Phase 1) we see that the frequency of ERS comes down whilst the level of anxiety, OCD belief and urges to seek reassurance stay the same. During the second phase of treatment (Tx Phase 2), Nick was helped to confront his fears using gradually more intensive behavioural experiments. Visual inspection shows a substantial change in ratings for all variables between treatment session 5 and 6 and ratings continue to come down for all variables during the remaining treatment sessions. Treatment phase 3 (Tx Phase 3) marks the beginning for when the treatment focus was directed more on treating Nick's excessive reassurance seeking. Again, we can see the same pattern for all variables, that is, scores become gradually lower and scores remain low throughout the relapse prevention phase (C). It should be noted that the sharp increases in ratings, which take place in phase 2,3 , and the relapse prevention phase coincide with particularly challenging behavioural experiments (represented in *), which were set up with Nick (or he decided to do himself; see examples of exact timings in Figure 1 and 2). As an example, this involved going to places he had avoided for years due to his contamination fears or being around certain people he considered contaminated. Finally, all treatment effects were maintained at 1 and 6-month follow-up (D).

- Figure 1 and Figure 2 to appear here -

Diagnostic tools and treatment outcome measures 
Table 1 shows Nick's outcome scores on the symptom and diagnostic measures from the initial assessment until the end of clinical contact. Nick's score on the Y-BOCS suggested that Nick was suffering from severe OCD at the start of treatment. By his last treatment sessions his score fell below the clinical cut-off of 8 and that progress was maintained both at 1 and 6-month follow-up. The same pattern emerged for the $\mathrm{OCl}$, i.e at the start of treatment his scores (59 points) were above the clinical cut-off of 40 points and at the end of treatment he scored 12 points and at the 6-month follow-up his scores had reduced to 10 points. The OCD-WOS gives insight into the time Nick spent engaging in compulsions and obsessions at the beginning of therapy and throughout treatment and follow-up. At the beginning of treatment, Nick was occupied for about 6-7 hours (sometimes over 7 hours) each day by his obsessions and compulsions. From session 17, this figure dropped to 0 and remained at this level during follow-up. In terms of depression and more general ratings of anxiety, Nick's score on the PHQ-9 never reached clinical cut-off for depression. Scores on the GAD-7 at the start of treatment indicated that he was suffering from moderate anxiety; from treatment session 10 and onwards he scored below the clinical cut-off point of 10 . Scores on the WSAS reduced from 2 points to 0 at both 1-month and 6-month follow-up. Finally, responsibility ratings (RAS) dropped from 126 to 71 at the 6-month follow up, indicating positive changes in inflated responsibility levels. His scores on the RIQ also from 68 to 4 points at 1-month follow-up and he scored 1 point on the same scale at 6-month follow-up. Changes in scores on the main standardized measures were reliable and clinically significant. 


\section{Discussion}

The aim of this study was to establish effectiveness of CBT in reducing symptoms of OCD including debilitating levels of reassurance seeking in a case where the problems are longstanding and CBT has previously been undertaken (within the last 3-4 years). However, these two treatment episodes have one thing in common; there was no specific focus on treating the participant's ERS.

The results of the single case quasi-experimental design suggest that $O C D$ and excessive reassurance seeking can be treated using CBT based on Salkovskis $(1985,1999)$ cognitive model of OCD and by helping the sufferer to shift from seeking reassurance to seeking support, even in severe and long-standing cases of OCD.

The treatment was split into several phases. The first phase focused on 'making sense of' the participant's problem using standard CBT techniques, such as developing an idiographic formulation of how the problem developed and was maintained. This involved helping the participant to test out how various reactions, such as seeking reassurance, were not a solution to his OCD but had become part of the problem. Reflecting on the treatment, the participant said that he found the time that was spent on drawing out his idiographic formulation and particularly the work on theory A versus B to be particularly helpful.

Achieving a clear understanding of how his OCD was maintained thus paved the way for the second phase of the treatment which focused on doing a range of behavioural experiments with the aim of challenging his beliefs by gathering information about 'how the world really works'. With increasingly more challenging behavioural experiments, the participant gradually started to feel differently about his problem. The most 'powerful' experiments involved deliberate contamination and delayed washing, sometimes over few days, to test 
out his predictions, which helped him to learn that his fears did not come true and that washing away his OCD was impossible. Given the severity of his washing compulsions these earlier stages of treatment focused on treating these as opposed to ERS.

With regards to ERS, the initial treatment intervention simply focused on making sense of the behaviour within the context of a 'vicious flower' (formulation) where the participant was helped to explore the short-term versus long-term effects of ERS on his OCD. As with other rituals, he was helped to understand how ERS maintained his problem and prevented him from overcoming his OCD. Helping him to make the shift from seeking reassurance to seeking support was not specifically introduced until halfway through treatment, simply because his washing and other cleaning rituals were given priority. Interestingly, the frequency of the behaviour had already dropped quite significantly (as well as all other ratings) before this intervention was specifically implemented. Reflecting on this change in ratings, the participant said that the formulation and behavioural experiments had taught him that although his washing rituals made him feel less anxious in the short-term it strengthened his OCD and this learning was generalized across other compulsions so he felt less motivated to seek reassurance. However, we know from clinical experience that low levels of reassurance seeking can equally maintain OCD problems and that certainly applied to this case. He was helped to make the shift from reassurance seeking to support seeking by identifying idiosyncratic examples of support seeking alternatives. For example, 'instead of asking $\mathrm{X}$ to say that I am clean, I will tell her that I feel anxious and ask her to come for a walk, or 'when I want X to watch me wash my hands to make sure I'm clean, I will instead ask her to remind me how good I always feel (and how proud she is) when I stand up to the OCD bully'. During this part of the treatment, it was particularly helpful to involve the 
participant's partner in some of the treatment sessions to discuss (and practice) how this could be applied. The therapist was in some contact with the partner in the following weeks where this 'technique' and its effectiveness were further discussed.

Without perfect control over the experimental conditions, one can only speculate whether this intervention explains the further decrease in the frequency of reassurance seeking, feelings of anxiety, urges to seek reassurance and OCD belief.

The main strength of the study is the number of data points that were collected which give very detailed information about the participant's progress throughout the course of treatment and during different intervention phases. Single case quasi-experimental designs can provide very valuable information, which can guide further research and treatment development, but have limitations. Firstly, it is not clear how well the effects will generalise. Secondly, several variables are being manipulated in each treatment session (given the severity of the patient's washing compulsions and contamination fears, meant that the focus on treatment had to be broad initially). Thus, it is difficult to judge how or if certain interventions were having an effect on the variables under investigation. A more tightly controlled, and potentially more powerful design, might have been an $A B C D$ design in which, after a baseline phase, the only instruction given to the patient was to drop ERS during the $B$ phase and then shift from ERS to seeking support during the $C$ phase. In addition, a direct measure of support seeking was not included, so this aspect depends on verbal feedback about whether the participant engaged in support seeking after it was introduced as a substitute for reassurance. If such a measure had been included, and a meaningful increase in support seeking had been observed during treatment phase 3 the 
strength of potential conclusions about the benefits of this intervention would have significantly increased.

A multiple-baseline single case experimental design would be the next step in taking this work forward given the relatively small number of older adults with severe OCD in clinical settings. For example, it would be interesting to compare the effects of ERP accompanied by a traditional habituation rationale with the effects of ERP delivered with a cognitive rationale (ERP-CR) where the participants are encouraged to either a) drop ERS or b) make the transition from reassurance seeking to support seeking. This is markedly different from the exposure interventions as conducted in traditional ERP because the ERP-CR condition is presented within an explicit framework that shifts participants to cognitive processing of the validity of their beliefs about reassurance seeking.

In summary, this clinical study illustrates how CBT can be successfully applied to treat long standing $O C D$ and excessive reassurance seeking in an older adult who had been suffering from OCD all his life. The participant had recently undergone two standard courses of CBT but soon after discharge relapsed. Those treatments were different from the one presented here on three main factors. Firstly, this treatment used a different approach to phrasing theory A/B; secondly, the behavioural experiments where the client was asked to contaminate and challenge his beliefs were considered by the client to be more challenging; and finally, emphasis was put on treating excessive reassurance seeking specifically. It is difficult to judge the extent to which each of these factors mattered. What these results obviously call for are further studies who control better for these different factors. 


\section{References}

Abramowitz, J. S., Franklin, M. E., \& Cahill, S. P. (2003). Approaches to common obstacles in the exposure-based treatment of obsessive-compulsive disorder. Cognitive and Behavioral Practice, 10(1), 14-22. doi:http://dx.doi.org/10.1016/S10777229(03)80004-4

Barlow, D. H., Nock, M. K., \& Hersen, M. (2008). Single case experimental designs: Strategies for studying behavior change. Boston: Pearson.

First, M. B., Spitzer, R. L., Gibbon, M., \& Williams, J. B. W. (1996). Structured Clinical Interview for DSM-IV Axis I Disorders. Washington, D. C.: American Psychiatric Press, Inc.

Foa, E. B., Kozak, M. J., Salkovskis, P. M., Coles, M. E., \& Amir, N. (1998). The validation of a new obsessive-compulsive disorder scale: The Obsessive-Compulsive Inventory. Psychological Assessment, 10(3), 206-214.

Foa, E. B., Liebowitz, M. R., Kozak, M. J., Davies, S., Campeas, R., \& Fraklin, M. E. e. a. (2005). Randomized, Placebo-Controlled Trial of Exposure and Ritual Prevention, Clomipramine, and Their Combination in the Treatment of Obsessive-Compulsive Disorder. The American Journal of Psychiatry, 162, 151-161.

Goodman, W. K., Price, L. H., Rasmussen, S. A., Mazure, C., Fleischmann, R. L., Hill, C. L., . . . Charney, D. S. (1989). The Yale-Brown obsessive compulsive scale: I. Development, use, and reliability. Archives of General Psychiatry, 46(11), 10061011.

Halldorsson, B., \& Salkovskis, P. M. (2017). Why Do People with OCD and Health Anxiety Seek Reassurance Excessively? An Investigation of Differences and Similarities in Function. Cognitive Therapy and Research, 1-13. doi:10.1007/s10608-016-9826-5

Halldorsson, B., Salkovskis, P. M., Kobori, O., \& Pagdin, R. (2015). I Do Not Know What Else To Do: Caregivers' Perspective on Reassurance Seeking in OCD. Journal of Obsessive-Compulsive and Related Disorders.

Halldorsson, B., Salkovskis, P. M., Kobori, O., \& Pagdin, R. (2016). I do not know what else to do: Caregivers' perspective on reassurance seeking in OCD. Journal of Obsessive-Compulsive and Related Disorders, 8, 21-30.

Houghton, S., Saxon, D., Bradburn, M., Ricketts, T., \& Hardy, G. (2010). The effectiveness of routinely delivered cognitive behavioural therapy for obsessive-compulsive disorder: A benchmarking study. British Journal of Clinical Psychology, 49(4), 473489.

Kobori, O., \& Salkovskis, P. M. (2013). Patterns of reassurance seeking and reassurancerelated behaviours in OCD and anxiety disorders. Behav Cogn Psychother, 41(1), 123. doi:10.1017/S1352465812000665

Kobori, O., Salkovskis, P. M., Read, J., Lounes, N., \& Wong, V. (2012). A qualitative study of the investigation of reassurance seeking in obsessive-compulsive disorder. Journal of Obsessive-Compulsive and Related Disorders, 1(1), 25-32.

Kroenke, K., Spitzer, R. L., \& Williams, J. B. (2001). The PHQ-9: validity of a brief depression severity measure. Journal of General Internal Medicine, 16, 606-613.

Marks, I. M. (2005). Living with Fear: Understanding and Coping with Anxiety (Second edition ed.). Glasgow: McGraw-Hill. 
Mundt, J. C., Marks, I. M., Shear, M. K., \& Greist, J. M. (2002). The Work and Social Adjustment Scale: a simple measure of impairment in functioning. The British Journal of Psychiatry, 180(5), 461-464. doi:10.1192/bjp.180.5.461

Ong, C. W., Clyde, J. W., Bluett, E. J., Levin, M. E., \& Twohig, M. P. (2016). Dropout rates in exposure with response prevention for obsessive-compulsive disorder: What do the data really say? Journal of anxiety disorders, 40, 8-17. doi:http://dx.doi.org/10.1016/i.janxdis.2016.03.006

Parrish, C. L., \& Radomsky, A. S. (2010). Why do people seek reassurance and check repeatedly? An investigation of factors involved in compulsive behavior in OCD and depression. Journal of anxiety disorders, 24(2), 211-222.

Parrish, C. L., \& Radomsky, A. S. (2011). An Experimental Investigation of Factors Involved in Excessive Reassurance Seeking: The Effects of Perceived Threat, Responsibility and Ambiguity on Compulsive Urges and Anxiety. Journal of Experimental Psychopathology, 2(1), 44-62.

Peris, T. S., Bergman, R. L., Langley, A., Chang, S., McCracken, J. T., \& Piacentini, J. (2008). Correlates of Accommodation of Pediatric Obsessive-Compulsive Disorder: Parent, Child, and Family Characteristics. Journal of the American Academy of Child \& Adolescent Psychiatry, 47(10), 1173-1181. doi:http://dx.doi.org/10.1097/CHI.0b013e3181825a91

Rachman, S. (1976). Obsessional-compulsive checking. Behaviour Research and Therapy, 14(4), 269-277. doi:http://dx.doi.org/10.1016/0005-7967(76)90002-4

Rachman, S. (2002). A cognitive theory of compulsive checking. Behaviour Research and Therapy, 40(6), 625-639.

Rachman, S., \& Hodgson, R. (1980). Obsessions and compulsions. Englewood Cliffs, NJ: Prentice Hall.

Salkovskis, P. M. (1985). Obsessional-compulsive problems: a cognitive-behavioural analysis. Behaviour Research and Therapy, 23(5), 571-583.

Salkovskis, P. M. (1991). The Importance of Behavior in the Maintenance of Anxiety and Panic - a Cognitive Account. Behavioural Psychotherapy, 19(1), 6-19.

Salkovskis, P. M. (1996a). Avoidance Behaviour is Motivated by Threat Beliefs: A Possible Resolution of the Cognitive-Behaviour Debate. In P. M. Salkovskis (Ed.), Trends in Cognitive and Behavioural Therapies (pp. 25-41). Oxford: John Wiley \& Sons.

Salkovskis, P. M. (1996b). The Cognitive Approach to Anxiety: Threat Beliefs, SafetySeeking Behavior, and the Special Case of Health Anxiety and Obsessions. In P. M. Salkovskis (Ed.), Frontiers of Cognitive Therapy (pp. 48-74). New York: The Guilford Press.

Salkovskis, P. M. (1999). Understanding and treating obsessive-compulsive disorder. Behaviour Research and Therapy, 37(Suppl 1), S29-52.

Salkovskis, P. M., \& Kobori, O. (2015). Reassuringly calm? Self-reported patterns of responses to reassurance seeking in obsessive compulsive disorder. J Behav Ther Exp Psychiatry. doi:10.1016/j.jbtep.2015.09.002

Salkovskis, P. M., \& Warwick, H. M. (1986). Morbid preoccupations, health anxiety and reassurance: a cognitive-behavioural approach to hypochondriasis. Behaviour Research and Therapy, 24(5), 597-602.

Salkovskis, P. M., Wroe, A. L., Gledhill, A., Morrison, N., Forrester, E., Richards, C., . . Thorpe, S. (2000). Responsibility attitudes and interpretations are characteristic of obsessive compulsive disorder. Behaviour Research and Therapy, 38(4), 347-372. 
Shafran, R., Radomsky, A. S., Coughtrey, A. E., \& Rachman, S. (2013). Advances in the Cognitive Behavioural Treatment of Obsessive Compulsive Disorder. Cognitive Behaviour Therapy, 1-10. doi:10.1080/16506073.2013.773061

Shafran, R., Ralph, J., \& Tallis, F. (1995). Obsessive-compulsive symptoms and the family. Bulletin of the Menninger Clinic, 59(4), 472-479.

Spitzer, R. L., Kroenke, K., Williams, J. B., \& Lowe, B. (2006). A brief measure for assessing generalized anxiety disorders: The GAD-7. Archives of Internal Medicine, 166, 1092-1097.

Stewart, S. E., Beresin, C., Haddah, S., Stack, D., Farna, J., \& Jenike, M. (2008). Predictors of family accommodation in obsessive-compulsive disorder. Annals of Clinical Psychiatry, 20(2), 65-70. doi:10.1080/10401230802017043

Storch, E. A., Geffken, G. R., Merlo, L. J., Jacob, M. L., Murphy, T. K., Goodman, W. K., ... Grabill, K. (2007). Family Accommodation in Pediatric Obsessive-Compulsive Disorder. Journal of Clinical Child \& Adolescent Psychology, 36(2), 207-216. doi:10.1080/15374410701277929 
Table 1. Participant's scores on clinical measures

\begin{tabular}{|c|c|c|c|c|c|c|c|c|c|c|c|c|c|c|c|c|c|c|c|c|c|}
\hline \multirow[b]{2}{*}{ Measures } & \multirow{2}{*}{$\begin{array}{c}\text { Baseline } \\
\text { (Assessment) } \\
\text { A }\end{array}$} & \multicolumn{4}{|c|}{$\begin{array}{c}\text { Phase } 1 \\
\text { Treatment sessions 1- } \\
4 \\
\text { B }^{1}\end{array}$} & \multicolumn{5}{|c|}{$\begin{array}{c}\text { Phase } 2 \\
\text { Treatment sessions 5-9 } \\
\text { B }^{1} B^{2}\end{array}$} & \multicolumn{6}{|c|}{$\begin{array}{c}\text { Phase } 3 \\
\text { Treatment sessions 10-15 } \\
B^{1} B^{2} B^{3}\end{array}$} & \multicolumn{3}{|c|}{$\begin{array}{c}\text { Relapse } \\
\text { prevention 16-18 } \\
\text { C }\end{array}$} & \multicolumn{2}{|c|}{$\begin{array}{l}\text { Monitoring } \\
\text { Month } \\
\text { D }\end{array}$} \\
\hline & & 1 & 2 & 3 & 4 & 5 & 6 & 7 & 8 & 9 & 10 & 11 & 12 & 13 & 14 & 15 & 16 & 17 & 18 & 1 & 6 \\
\hline Y-BOCS & 35 & - & - & - & - & - & - & - & - & - & - & - & - & - & - & - & - & - & 7 & 7 & 5 \\
\hline $\mathrm{OCl}$ & 58 & 59 & 83 & $*$ & $*$ & $*$ & 60 & 55 & 49 & 50 & 49 & 23 & 10 & 24 & 24 & 32 & 22 & 11 & 12 & 10 & 10 \\
\hline \multicolumn{22}{|l|}{ OCD - WOS } \\
\hline Time (hrs) & $5-6$ & $5-6$ & $>7$ & $>7$ & $3-4$ & $5-6$ & $1-2$ & $2-3$ & $1-2$ & $1-2$ & $0-1$ & $1-2$ & $0-1$ & $0-1$ & $0-1$ & $*$ & $*$ & 0 & 0 & 0 & 0 \\
\hline Distress & $8 / 8$ & $8 / 8$ & $8 / 8$ & $6 / 8$ & $6 / 8$ & $8 / 8$ & $6 / 8$ & $5 / 8$ & $6 / 8$ & $6 / 8$ & $4 / 8$ & $3 / 8$ & $2 / 8$ & $2 / 8$ & $2 / 8$ & $*$ & $*$ & $1 / 8$ & $1 / 8$ & $1 / 8$ & $1 / 8$ \\
\hline Handicap & $6 / 8$ & $6 / 8$ & $6 / 8$ & $6 / 8$ & $4 / 8$ & $5 / 8$ & $5 / 8$ & $1 / 8$ & $4 / 8$ & $2 / 8$ & $2 / 8$ & $0 / 8$ & $0 / 8$ & $2 / 8$ & $2 / 8$ & $*$ & $*$ & $0 / 8$ & $0 / 8$ & $0 / 8$ & $0 / 8$ \\
\hline Avoidance & $8 / 8$ & $8 / 8$ & $8 / 8$ & $8 / 8$ & $6 / 8$ & $6 / 8$ & $6 / 8$ & $6 / 8$ & $4 / 8$ & $2 / 8$ & $4 / 8$ & $1 / 8$ & $2 / 8$ & $4 / 8$ & $3 / 8$ & $*$ & $*$ & $0 / 8$ & $0 / 8$ & $0 / 8$ & $0 / 8$ \\
\hline PHQ-9 & 6 & 6 & 6 & 7 & 8 & 3 & 5 & 3 & 2 & 2 & 3 & 0 & 1 & 2 & 2 & 2 & 0 & 0 & 0 & 0 & 0 \\
\hline GAD-7 & 12 & 12 & 13 & 10 & 14 & 11 & 12 & 6 & 8 & 10 & 5 & 3 & 1 & 3 & 3 & 3 & 3 & 0 & 3 & 0 & 0 \\
\hline WSAS & 2 & 2 & 8 & 8 & 4 & 2 & 5 & 2 & 1 & 2 & 2 & 4 & 1 & 0 & 1 & 0 & 0 & 0 & 0 & 0 & 0 \\
\hline RAS & 126 & - & - & - & - & - & - & 120 & - & - & - & - & - & - & 90 & - & - & - & - & 112 & 72 \\
\hline RIQ & 68 & - & - & - & - & - & - & 23 & - & - & - & - & - & - & 13 & - & - & - & - & 4 & 1 \\
\hline
\end{tabular}

Note: SCID, Structured Clinical Interview for Diagnostic and Statistical Manual for DSM-IV Axis I Disorders; Y-BOCS, Yale-Brown Obsessive Compulsive Scale; OCI, Obsessive Compulsive Inventory; OCD - WOS: OCD Weekly Outcome Score; PHQ-9, Patient Health Questionnaire-9; GAD-7, Generalized Anxiety Disorder-7; RAS, Responsibility Attitude Scale; RIQ, Responsibility Interpretations Questionnaire; IA: Initial assessment; * missing 


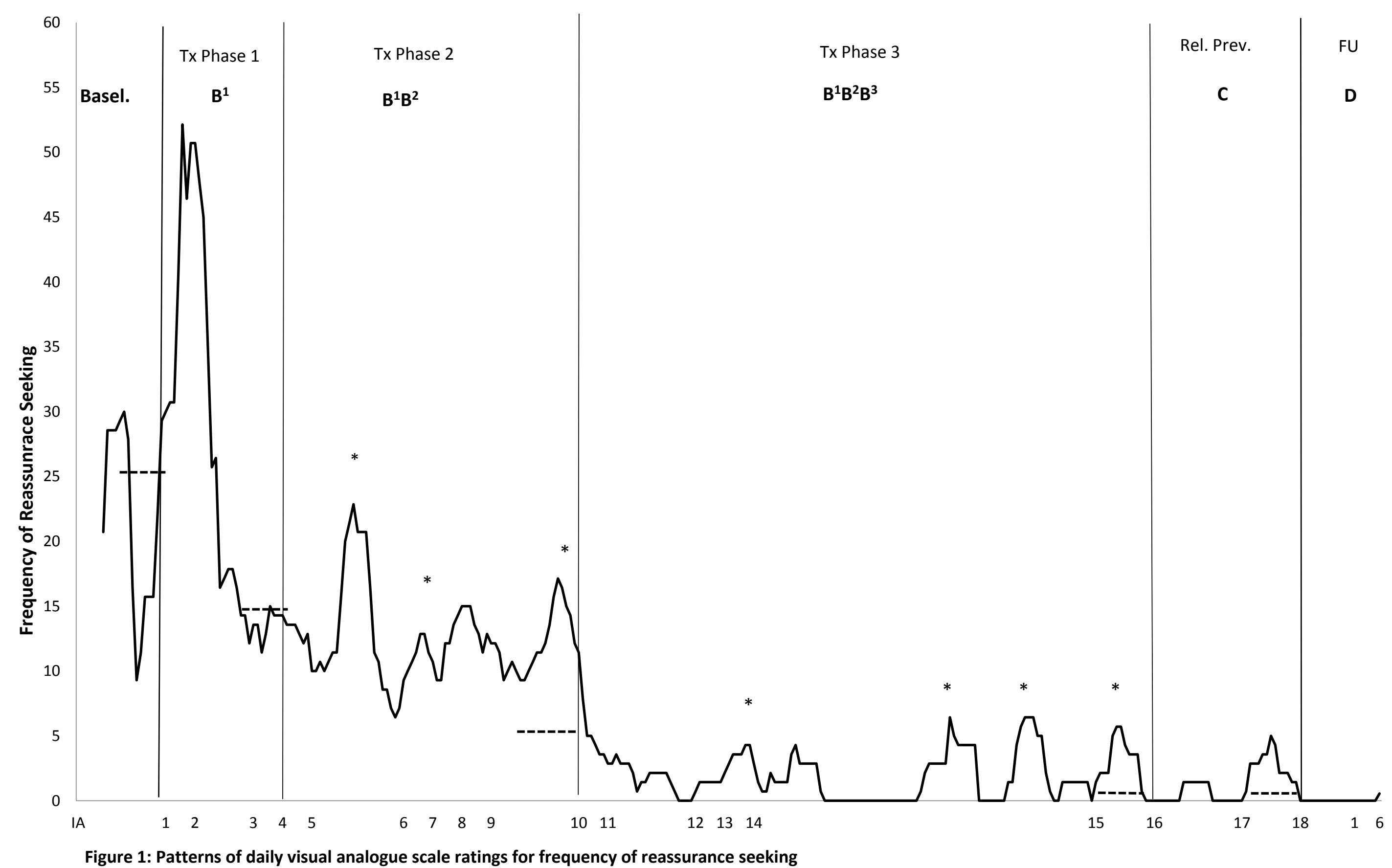

Note: FU = Follow-up; Black dotted lines = Median scores for the last seven data points in each phase; ${ }^{*}=$ particularly challenging behavioural experiments 


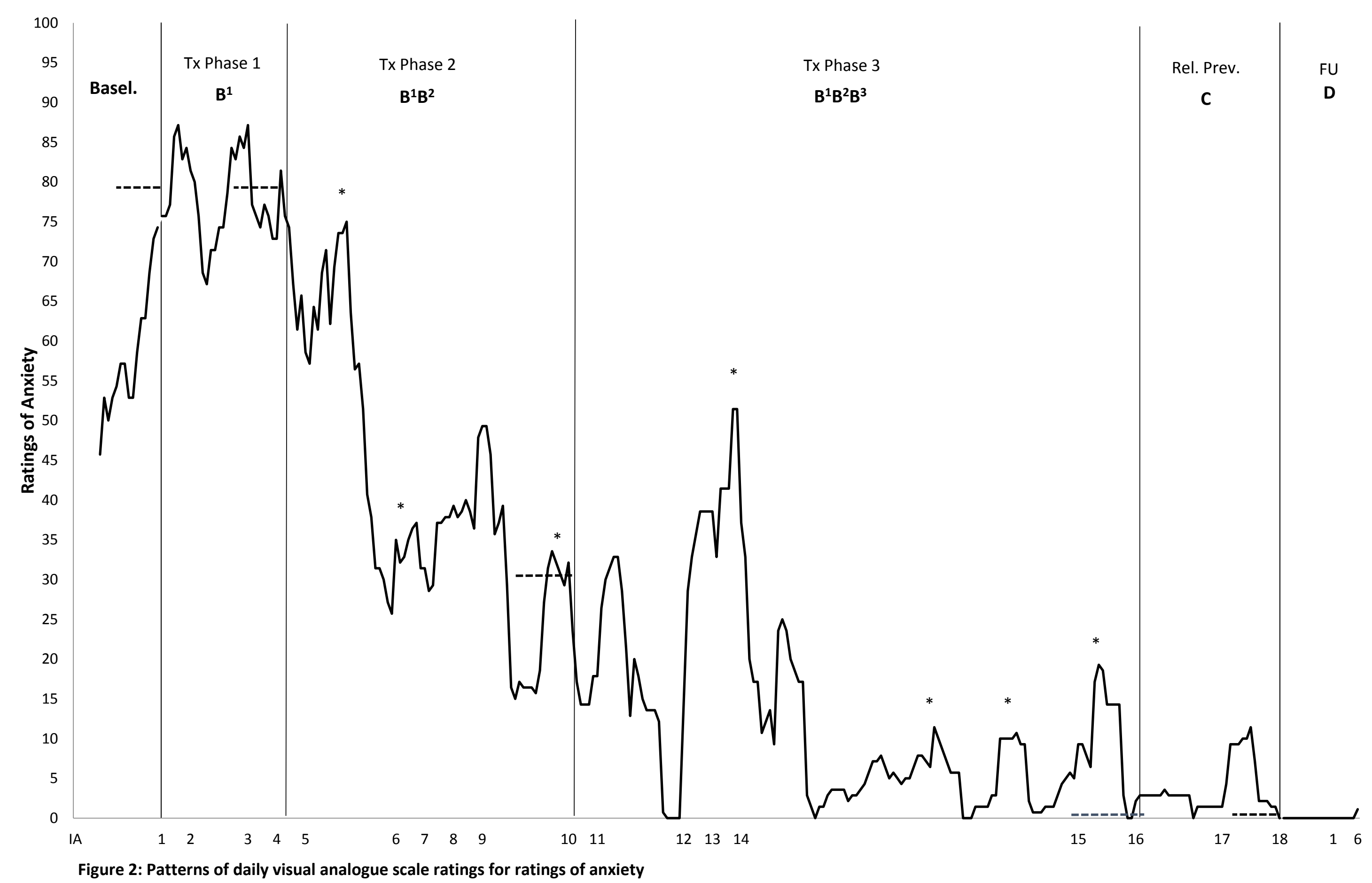

Note: FU = Follow-up; Black dotted lines = Median scores for the last seven data points in each phase; ${ }^{*}=$ particularly challenging behavioural experiments 